\title{
Recherche de porte-greffes de vigne résistant à la transmission du virus du court-noué (GFV) par le nématode Xiphinema index Thorne \& Allen. I. - Application de la méthode ELISA à la réalisation d'un test rapide de sélection
}

\author{
Alain BOUQUET \& Yves DANGLOT
}

I.N.R.A., Station de Recherches de Viticulture, Centre de Recherches de Bordeaux, F33140 Pont-de-la-Maye

RÉSUMÉ La sélection de porte-greffes de vigne résistant à la transmission du virus du court-noué (GFV) par son
nématode vecteur Xiphinema index est une alternative séduisante aux méthodes de lutte actuellement
pratiquées contre ce parasite.
Il est possible d'évaluer rapidement la résistance des plantes à la transmission du virus en détectant
directement, au moyen du test immunoenzymatique ELISA, la présence du virus dans les racines mises au
contact du nématode. L'application de cette technique à plusieurs variétés de vigne «muscadine "
(Muscadinia rotundifolia) confirme le haut niveau de résistance récemment mis en évidence chez cette espèce.

Mots clés additionnels : Vitis, muscadinia rotundifolia, test immunoenzymatique, vecteur, racines.

Search for grape rootstocks resistant to the transmission of grape fanleaf virus (GFV) by the nematode Xiphinema index Thorne \& Allen.

I. - Enzyme-linked immunosorbent assay as a quick method of selection.

The selection of grape rootstocks resistant to the transmission of grape fanleaf virus (GFV) by its vector nematode Xiphinema index, is an attractive alternative to the current methods of disease control. It was possible to test the resistance of plants to transmission of the virus, detecting directly by enzyme-linked immunosorbent assay (ELISA) the presence of GFV in roots inoculated with the nematode. Application of this technique to some varieties of muscadine grape (Muscadinia rotundifolia) confirmed the high level of resistance recently observed in this species.

Additional key words : Vitis, muscadinia rotundifolia, immunosorbent assay, vector, roots.

\section{INTRODUCTION}

Grâce à un travail rigoureux de sélection clonale et sanitaire mené conjointement par l'I.N.R.A. et l'ANTAV (*) au cours des deux dernières décennies, les viticulteurs français disposent à l'heure actuelle de matériel certifié, exempt de certains virus et notamment du virus responsable de la maladie du court-noué (GFV $=$ Grape fanleaf virus). Le court-noué, également appelé dégénéres-

(*) ANTAV $=$ Association Nationale Technique pour l'Amélioration de la Viticulture, Domaine de l'Espiguette, 30240 Le Graudu-Roi. cence infectieuse, est actuellement la maladie à virus la plus grave connue sur la vigne. Depuis les travaux de HEwITT $e t$ al. (1958), on sait que l'agent causal, qui appartient au groupe des népovirus, est transmis par un vecteur souterrain, le nématode Xiphinema index Thorne \& Allen de la famille des Longidoridae. Le rôle vecteur de $X$. index dans la dissémination du virus du court-noué en Europe a été confirmé notamment par les travaux de VuITTENEZ et al. (1972). En France, les sols viticoles contaminés par ce nématode couvrent des superficies considérables, en particulier dans la région méditerranéenne (DALMASSO, 1970). La seule méthode vraiment efficace d'éradication du parasite consiste en un repos du sol de longue durée (5 à 7 ans), 
qui est le plus souvent irréalisable pour des raisons économiques faciles à comprendre. Les viticulteurs désirant remplacer de vieilles vignes malades par du matériel sain ne peuvent actuellement que se prémunir temporairement contre les risques de recontamination virale de leurs parcelles par une désinfection préventive du sol au moyen de traitements fumigants onéreux, souvent polluants et d'efficacité quelquefois aléatoire (VUITTENEZ, 1960 ; DALMASSO, 1978).

Face à cette situation, la sélection de porte-greffes résistant à la transmission du virus apparait comme une alternative extrémement séduisante, s'intégrant parfaitement dans le cadre d'une protection "raisonnée " du vignoble, qui tiendrait compte de l'ensemble des facteurs biologiques susceptibles d'agir sur l'épidémiologie des parasites.

Confrontés aux mêmes problèmes, les chercheurs californiens se sont orientés vers la sélection de porte-greffes combinant un certain niveau de résistance à $X$. index, obtenu à partir d'espèces telles que Vitis rufotomentosa Small ou $V$. arizonica Engel. (KUNDE et al., 1968 ; MEREDITH et al., 1982), et une ou plusieurs résistances à la multiplication virale, qui auraient été récemment mises en évidence dans le genre Vitis, mais également chez certains cépages de $V$. vinifera L. (JIMENEZ, 1980).

En France, Boubals \& PISTRE (1978) ont observé que des plants de l'espèce Muscadinia rotundifolia Small (synonyme Vitis rotundifolia Michx), inoculés au moyen de $X$. index virulifères, ne manifestaient 5 ans après, aucun symptôme foliaire de court-noué, à la différence de toutes les autres espèces du genre Vitis et des porte-greffes classiques inoculès dans les mêmes conditions. Nous avons développé les recherches dans cette voie et montré, notamment au moyen d'inoculations par greffage, qu'il ne s'agissait pas d'un phénomène de tolérance au virus mais bien d'une résistance à la transmission du court-noué par son nématode vecteur (BOUQUET, 1981).

Le test immunoenzymatique ELISA est actuellement couramment utilisé pour la détection du virus du court-noué dans les jeunes feuilles ou les bourgeons dormants de vignes infectées (WALTER et al., 1979; BOVEY et al., 1980; ShanmuganathaN, 1982). Cependant, on sait que le virus du court-noué inoculé dans les racines d'un plant de vigne par $X$. index, met un certain temps à migrer dans la plante entière, ce qui présente l'inconvénient de rendre possibles les interprétations erronées si les tests de détection du virus sont faits trop précocément sur les parties aériennes du végétal. Pour pallier cet inconvénient nous avons utilisé une méthode permettant d'évaluer rapidement la résistance des plantes à la transmission du virus en détectant directement, au moyen du test ELISA, la présence du virus dans les racines mises au contact du nématode vecteur. En effet, VUITTENEZ et ai. (1972) ont montré l'efficacité de la recherche directe du virus dans les pointes de racines, par l'inoculation mécanique sur plantes herbacées ou les tests sérologiques, notamment les tests au latex.

\section{MATÉRIEL ET MÉTHODES}

\section{A. Matériel}

\section{Vigne}

Les essais d'inoculation et de détection du virus ont été réalisés essentiellement sur un clone sain du porte-greffe
Vitis riparia Michx cv «Gloire», connu pour sa relative tolérance aux attaques de $X$. index (KUNDE et al., 1968 ; BOUBALS \& PISTRE, 1978). Nous avons également utilisé un clone sain du porte-greffe Vitis rupestris Scheele cv « du Lot », beaucoup plus sensible au nématode. Quant aux variétés appartenant à l'espèce $M$. rotundifolia, considérée comme résistante, elles ont été multipliées par bouturage herbacé à partir de plants racinés introduits de Caroline du Nord (Prof. W. B. NesBiTT, Université de Raleigh N.C., U.S.A.).

\section{Nématodes}

La population de $X$. index provient d'un isolement effectué par A. DALMASSO dans un vignoble de Blanquefort, près de Bordeaux. Elle est multipliée en permanence sur les racines de figuiers cultivés en serre dans des pots remplis de terre sablo-limoneuse désinfectée à la vapeur. L'influence de la température du sol est très importante : CoIro et al. (1980) ont en effet montré que, sur figuier, la température du sol la plus favorable au développement de $X$. index était $22^{\circ} \mathrm{C}$. A $16^{\circ} \mathrm{C}$, le taux de multiplication du nématode est environ 100 fois plus faible.

\section{Virus}

La souche de virus utilisée (grape fanleaf virus) provient d'un clone de la variété indicatrice $V$. rupestris $\mathrm{cv}$ « du Lot », manifestant depuis plus de 15 ans des symptômes accusés de fanleaf. Elle a été testée sérologiquement et vérifiée exempte d'autres virus, notamment d'Arabis mosaic virus (AMV), afin d'éviter tout risque d'interaction entre souches de népovirus affectant la vigne (VUITTENEZ et al., 1978).

\section{Immunoglobulines}

L'immunsérum anti-GFV a été fourni par A. VUITTENEZ (Station de Pathologie végétale I.N.R.A., 68021 Colmar). Son titre, déterminé par double diffusion en milieu gélosé, est de 1/4000. Les immunoglobulines (IgG) ont été purifiées par chromatographie d'affinité sur colonne de SépharoseProtéine A. Le couplage des IgG avec la phosphatase alcaline (Sigma type VII) a été réalisée en présence de glutaraldéhyde.

\section{B. Méthodes}

\section{Acquisition du virus par les nématodes}

L'extraction des nématodes des pots servant à leur élevage est faite au moyen d'une technique simplifiée de décantation et tamisage (DALMASSO, 1966). A titre indicatif, la population de nématodes récupérée sur un seul figuier cultivé pendant 5 ans dans un volume de sol de $5 \mathrm{dm}^{3}(600 \mathrm{~g}$ de racines environ) s'est élevée à plus de 150000 individus (adultes et larves du $3^{\mathrm{e}}$ et $4^{\mathrm{e}}$ stades). Rappelons que les densités couramment observées dans la nature (sols de vignes) dépassent rarement quelques dizaines d'individus par kg de terre (DALMASSO, 1970).

Les nématodes sont rendus virulifères par un séjour de plusieurs mois dans des pots contenant des plants racinés de $V$. rupestris cv « du Lot " atteints de court-noué. L'acquisition du virus peut être contrôlée directement en appliquant un test ELISA à des échantillons de 50 nématodes broyés dans des micropotters contenant $500 \mu \mathrm{l}$ de tampon d'extraction (BouQueT, 1983). 


\section{Inoculation $d u$ virus}

L'inoculation est faite sur des boutures racinées âgées de 6 mois environ, cultivées dans des pots en plastique de $250 \mathrm{~cm}^{3}$ remplis d'un mélange en parties égales de sable de rivière, tourbe et perlite. La suspension de nématodes utilisée pour la contamination est déposée dans un trou à la base de la bouture. Les plantes sont alors cultivées en serre pendant 3 mois, le contenu des pots étant soigneusement maintenu humide au moyen d'un arrosage quotidien effectué à l'eau pure car les solutions nutritives utilisées pour la culture de la vigne en serre ont un effet dépressif sur l'activité des nématodes. Au bout de 3 mois, les plantes sont dépotées, les extrémités des racines sont prélevées, soigneusement lavées et conservées $24 \mathrm{~h}$ à $+4{ }^{\circ} \mathrm{C}$ avant d'être testées sérologiquement.

\section{Réalisation des tests ELISA}

Les tests ELISA sont réalisés dans des plaques de microtitration Dynatech M $129 \mathrm{~B}$ selon la technique «sandwich " (CLARK \& ADAMS, 1977). Des essais préliminaires ont montré que des résultats extrêmement satisfaisants étaient obtenus avec une concentration des IgG utilisés en «coating " variant de 0,5 à $1 \mu \mathrm{g} / \mathrm{ml}$ et une dilution du conjugué IgG-enzyme variant de $\frac{1}{2000}$ à $\frac{1}{3000}$.

Dans cette "fourchette " d'utilisation des anticorps, les réactions non spécifiques sont pratiquement nulles. Les échantillons à tester sont préparés par broyage des racines en présence d'une solution d'extraction composée du tampon PBS-Tween additionné de polyvinylpyrrolidone (PVP) à 2 p. 100 et de nicotine à 2,5 p. 100 . L'extraction est effectuée au moyen d'un broyeur-homogénéiseur POLYTRON dans des tubes Pyrex de $25 \mathrm{~mm}$ de diamètre, refroidis dans de la glace pilée. Des essais préliminaires ont en effet montré que l'extraction du virus au moyen d'un POLYTRON était aussi efficace et beaucoup plus rapide qu'une extraction par broyage au mortier. Dans les 2 cas, le rapport optimal poids de racines/volume du milieu d'extraction est compris entre 0,2 et 0,4 , c'est-à-dire 1 à $2 \mathrm{~g}$ de racines pour $5 \mathrm{ml}$ de tampon. Le type de racines utilisées (pointes de racines charnues, chevelu racinaire fin ou fragments de troncs radiculaires lignifiés) n'a pas d'influence significative sur l'efficacité du test.

Le broyat est filtré sur étamine, puis centrifugé pendant $15 \mathrm{~min}$ à $2000 \mathrm{~g}$; cette double manipulation a l'avantage d'augmenter de plus de 40 p. 100 l'efficacité du test, par rapport à une simple décantation ou une simple filtration, et de près de 20 p. 100 , par rapport à une simple centrifugation. Le surnageant est récupéré et déposé dans les plaques de microtitration à raison de $250 \mu \mathrm{l}$ par puits. Deux puits contigus sont utilisés par échantillon et 12 puits par plaque sont réservés aux échantillons sains témoins.

Après au moins $1 \mathrm{~h}$ d'incubation du substrat à la température du laboratoire, les lectures (densité optique à $405 \mathrm{~nm}$ ) sont faites à intervalles réguliers, grâce à un lecteur de plaques BIOMERIEUX LOV 1 couplé à un calculateur HP $97 \mathrm{~S}$ donnant directement les différences de densité optique (D.D.O.) entre les échantillons testés et les échantillons témoins situés sur une même ligne de la plaque de microtitration. Lorsqu'elles sont faibles, c'est-à-dire inférieures à 0,1 , seuil couramment utilisé pour le dépistage systématique de certaines maladies à virus chez les arbres fruitiers (PRACRos et al., 1981), ces différences peuvent être statistiquement testées par la méthode de la comparaison de 2 échantillons de taille $\left(n_{1}=2 ; n_{2}=12\right)$ et de variances inégales, ce qui permet de tenir compte de la fluctuation entre puits due en particulier à l'hétérogénéité de certaines plaques (réactions enzymatiques parfois plus rapides à la périphérie des plaques qu'au centre de celles-ci). Il est également possible d'appliquer un seuil fixé en fonction de la fluctuation enregistrée dans les échantillons témoins : les D.D.O. entre les échantillons testés et la moyenne des échantillons témoins sont considérées positives lorsqu'elles sont supérieures à 3 fois l'écart-type de la densité optique des échantillons témoins (BOVEY et al., 1980).

\section{RÉSULTATS ET DISCUSSION}

\section{A. Influence de l'inoculum sur l'efficacité du test ELISA}

Le tableau 1 montre l'influence de la densité de l'inoculum (nombre de $X$. index virulifères par plante) sur l'aptitude du test ELISA à déceler la présence du virus dans des racines du porte-greffe $V$. riparia cv «Gloire », 3 mois après leur inoculation.

L'examen des D.D.O. enregistrées montre immédiatement l'existence d'un seuil très net se situant entre 100 et 250 nématodes par plante. La réalité de ce seuil doit cependant être considérée avec circonspection. En effet, les lots de 1 à $100 X$. index ont été constitués de nématodes adultes prélevés individuellement dans la suspension aqueuse obtenue par décantage et tamisage du contenu des pots ayant servi à l'acquisition du virus par les nématodes. Il n'est pas exclu que la méthode de prélèvement ait entraîné la mort d'un nombre plus ou moins élevé d'individus, diminuant d'autant la densité réelle de l'inoculum.

A l'opposé, les lots de 250 à 1000 nématodes ont été constitués par des fractions aliquotes de la suspension dont la concentration avait été préalablement déterminée. Or, les dénombrements n'ont en fait pris en compte que les nématodes adultes et les stades larvaires $\mathrm{L}_{3}$ et $\mathrm{L}_{4}$ facilement repérables. On peut donc considérer que, pour ces lots, les densités réelles de l'inoculum (incluant les formes larvaires $L_{1}$ et $L_{2}$ ) étaient sensiblement supérieures à celles indiquées. Enfin, il ne faut pas sous-estimer l'importance des pertes éventuelles par drainage bien que la technique et le milieu d'inoculation aient été spécialement conçus pour limiter au maximum ces pertes. Cependant, le faible taux de réussite des inoculations observé avec les lots de 100 nématodes ne manque pas d'être surprenant. Une évaluation de la population au moment de l'examen des racines, qui n'a malheureusement pas pu être faite par manque de temps, aurait pu apporter éventuellement un début d'explication à cette anomalie.

Quoi qu'il en soit, les résultats de cet essai montrent clairement que les tests ELISA, pratiqués sur les racines d'une espèce relativement tolérante à $X$. index 3 mois après leur mise au contact de nématodes virulifères, ne permettent de détecter significativement la présence du virus, donc de mettre en évidence la réalité de sa transmission, que si des inoculums relativement importants ont été utilisés, inoculums qui ne doivent pas être inférieurs à 250 nématodes par plante.

Cependant, même dans les cas les plus favorables, le pourcentage de plantes inoculées réagissant positivement au test ELISA n'atteint jamais 100 p. 100 . En fait, l'absence de réaction sur certaines plantes inoculées avec des quantités élevées de nématodes est essentiellement due au fait que les racines prélevées sur ces plantes étaient en très mauvais 


\section{TABLEAU 1}

Influence de la densité de l'inoculum (nombre de nématodes virulifêres par plante) sur la transmission du virus du court-noué (GFV) au portegreffe V. riparia $\mathrm{cv}$ "Gloire " au moyen de nématodes X. index. Résultats des tests ELISA pratiqués sur racines 3 mois après l'inoculation. Effect of inoculum density (number of viruliferous nematodes per plant) on the transmission of grape fanleaf virus to the rootstock $\mathrm{V}$. riparia $\mathrm{cv}$ "Gloire " by means of nematodes X. index. Results of immunosorbent assays (ELISA) performed on roots three months after inoculation.

\begin{tabular}{|c|c|c|c|c|c|c|c|c|c|}
\hline Temps d'hydrolyse du subs & trat & & $2 \mathrm{~h}$ & & $4 \mathrm{~h}$ & & $8 \mathrm{~h}$ & & $20 \mathrm{~h}$ \\
\hline $\begin{array}{l}\text { Densité optique témoins } \\
\text { non inoculés: } \\
405 \mathrm{~nm} \text { ) }\end{array}$ & $\begin{array}{l}\text { Moyenne } \\
\text { Ecart-type } \\
\text { C.V. \% }\end{array}$ & & $\begin{array}{r}0,107 \\
0,005 \\
4,6 \%\end{array}$ & & $\begin{array}{r}0,152 \\
0,007 \\
4,6 \%\end{array}$ & & $\begin{array}{r}0,219 \\
0,014 \\
6,4 \%\end{array}$ & & $\begin{array}{r}0,379 \\
0,037 \\
9,9 \%\end{array}$ \\
\hline $\begin{array}{l}\text { Différence de densité } \\
\text { optique témoin infecté } \\
\text { GFV (D.D.O. } 405 \mathrm{~nm} \text { ) }\end{array}$ & & & $>2,000$ & & $>2,000$ & & $>2,000$ & & $>2,000$ \\
\hline $\begin{array}{l}\text { D.D.O. plantes inocu- } \\
\text { lées : } \\
1 \text { néma/plante } \\
\text { ( } 8 \text { répétitions) }\end{array}$ & $\begin{array}{l}\text { Moyenne } \\
\text { Nbre } \\
\text { échant. } \\
\text { positifs }\left(^{*}\right)\end{array}$ & $0 / 8$ & $-0,003$ & $0 / 8$ & $-0,004$ & $0 / 8$ & $-0,004$ & $0 / 8$ & $-0,010$ \\
\hline $\begin{array}{l}5 \text { némas/plante } \\
\text { (8 répétitions) }\end{array}$ & $\begin{array}{l}\text { Moyenne } \\
\text { Nbre échant. }\end{array}$ & $+0 / 8$ & $-0,001$ & $0 / 8$ & $-0,002$ & $0 / 8$ & $-0,002$ & $0 / 8$ & $-0,002$ \\
\hline $\begin{array}{l}10 \text { némas/plante } \\
\text { (5 répétitions) }\end{array}$ & $\begin{array}{c}\text { Moyenne } \\
\text { Nbre échant. }\end{array}$ & $+0 / 5$ & $-0,005$ & $0 / 5$ & $-0,004$ & $0 / 5$ & 0,000 & $0 / 5$ & $+0,008$ \\
\hline $\begin{array}{l}25 \text { némas/plante } \\
\text { (5 répétitions) }\end{array}$ & $\begin{array}{l}\text { Moyenne } \\
\text { Nbre échant. }\end{array}$ & $+0 / 5$ & $-0,002$ & $0 / 5$ & $-0,001$ & $1 / 5$ & $\begin{array}{c}+0,009 \\
(+0,042)\end{array}$ & $0 / 5$ & $+0,019$ \\
\hline $\begin{array}{l}50 \text { némas/plante } \\
\text { (5 répétitions) }\end{array}$ & $\begin{array}{c}\text { Moyenne } \\
\text { Nbre échant. }\end{array}$ & $+0 / 5$ & $+0,006$ & $0 / 5$ & $+0,010$ & $3 / 5$ & $\begin{array}{l}+0,039 \\
(+0,050)\end{array}$ & $2 / 5$ & $\begin{array}{c}+0,082 \\
(+0,121)\end{array}$ \\
\hline $\begin{array}{l}100 \text { némas/plante } \\
\text { (5 répétitions) }\end{array}$ & $\begin{array}{l}\text { Moyenne } \\
\text { Nbre échant. }\end{array}$ & $+0 / 5$ & $+0,001$ & $0 / 5$ & $+0,004$ & $2 / 5$ & $\begin{array}{c}+0,031 \\
(+0,055)\end{array}$ & $2 / 5$ & $\begin{array}{c}+0,064 \\
(+0,140)\end{array}$ \\
\hline $\begin{array}{l}250 \text { némas/plante } \\
\text { (5 répétitions) }\end{array}$ & $\begin{array}{c}\text { Moyenne } \\
\text { Nbre échant. }\end{array}$ & $+4 / 5$ & $\begin{array}{c}+0,321\left(^{* *}\right) \\
(+0,401)(* * *)\end{array}$ & $4 / 5$ & $\begin{array}{c}+0,584 \\
(+0,735)\end{array}$ & $4 / 5$ & $\begin{array}{c}+0,808 \\
(>1,000)\end{array}$ & $4 / 5$ & $\begin{array}{l}>1,000 \\
(>1,500)\end{array}$ \\
\hline $\begin{array}{l}500 \text { némas/plante } \\
\text { (5 répétitions) }\end{array}$ & $\begin{array}{c}\text { Moyenne } \\
\text { Nbre échant. }\end{array}$ & $+4 / 5$ & $\begin{array}{c}+0,521 \\
(+0,652)\end{array}$ & $4 / 5$ & $\begin{array}{l}+0,880 \\
(>1,000)\end{array}$ & $4 / 5$ & $\begin{array}{l}>1,000 \\
(>1,200)\end{array}$ & $4 / 5$ & $\begin{array}{l}>1,000 \\
(>1,500)\end{array}$ \\
\hline $\begin{array}{l}1000 \text { némas/plante } \\
\text { (5 répétitions) }\end{array}$ & $\begin{array}{c}\text { Moyenne } \\
\text { Nbre échant. }\end{array}$ & $+3 / 5$ & $\begin{array}{c}+0,165 \\
(+0,278)\end{array}$ & $3 / 5$ & $\begin{array}{c}+0,329 \\
(+0,552)\end{array}$ & $3 / 5$ & $\begin{array}{l}+0,587 \\
(+0,939)\end{array}$ & $3 / 5$ & $\begin{array}{l}>1,000 \\
(>1,500)\end{array}$ \\
\hline
\end{tabular}

(*) D.D.O. échantillon supérieure à 3 fois l'écart-type de la D.O. des plantes non inoculées (BoveY et al., 1980).

(**) D.D.O. moyenne de l'ensemble des plantes inoculées.

$\left({ }^{* * *}\right)$ D.D.O. moyenne des plantes à réaction positive.

état, fortement nécrosées et en voie de décomposition. Il est possible que ces nécroses, particulièrement nettes sur les racines des plantes inoculées avec les plus fortes densités de nématodes, soient une conséquence des dégâts directs occasionnés par $X$. index, ce qui expliquerait en partie la chute de D.D.O. observée lorsque l'on passe d'un inoculum de 500 nématodes par plante à un inoculum de 1000 nématodes par plante.

Selon Boubals \& Pistre (1978), 2 types de dégâts provoqués par les piqûres de $X$. index peuvent être constatés sur les racines des espèces et variétés sensibles:

- d'une part, des nodosités sur les extrémités, renflements de forme souvent coralloïde, constitués de tissus spongieux, néoformés. Les extrémités radiculaires présen- tant ces symptômes caractéristiques ne sont plus en mesure d'assurer leur croissance normale. Elles sont cependant un matériel de choix pour la détection du virus par ELISA. Il faut noter que le nombre et les dimensions de ces nodosités ne sont pas très élevés chez $V$. riparia cv «Gloire», ce qui avait déjà été signalé par KUNDE et al. (1968) et par BOUBALS \& PISTRE (1978);

- d'autre part, des tubérosités sur les troncs radiculaires, tubérosités s'accompagnant souvent de nécroses des tissus sous-jacents (écorce et liber) qui peuvent dans certains cas occasionner de véritables incisions annulaires entraînant la mort des extrémités radiculaires, mais qui peuvent être également des foyers d'infection par des microorganismes fongiques ou bactériens susceptibles de 
provoquer une décomposition rapide des tissus si les conditions du milieu, température et humidité notamment, sont favorables.

Il est évident que des racines présentant à un niveau élevé ce type de dégâts ne sont pas un terrain très favorable à la multiplication du virus inoculé : l'efficacité du test ELISA en est diminuée d'autant. L'interprétation de résultats négatifs doit donc être prudente et tenir compte en premier lieu de l'état général des systèmes racinaires sur lesquels sont pratiqués les tests.

Il aurait été sans doute utile, pour les concentrations élevées en nématodes, d'éliminer le vecteur par un traitement adéquat, un mois après l'inoculation, de façon à éviter ces dégâts directs qui nuisent à la multiplication du virus.

\section{B. Influence du temps d'hydrolyse du substrat sur la} sensibilité du test ELISA

Un autre enseignement que l'on peut tirer de la lecture du tableau 1, est l'intérêt qu'il peut y avoir à prolonger le temps d'hydrolyse du substrat pour augmenter la sensibilité du test ELISA et détecter ainsi de faibles concentrations d'antigène, comme l'ont montré PRACROS et al. (1981) avec certains virus des arbres fruitiers (CLSV notamment) et comme nous l'avons également montré en détectant par ELISA la présence du virus du court-noué dans des lots de quelques nématodes (BouQUET, 1983).

Naturellement, il est indispensable que le système IgGconjugué utilisé ne présente pas de réactions non spécifiques. Celles-ci peuvent être caractérisées par les valeurs du coefficient de variation de la densité optique des témoins sains. Dans le cas présent, ce coefficient varie de 4,6 à 6,4 p. 100 pour des temps d'hydrolyse de 2 à $8 \mathrm{~h}$. Par contre, il atteint près de 10 p. 100 au bout de $20 \mathrm{~h}$.

Il semble qu'une hydrolyse d'une durée de $8 \mathrm{~h}$ soit optimale puisque, dans ce cas, le test ELISA détecte significativement la présence de traces de virus dans 6 plantes sur 15 , inoculées avec des concentrations de nématodes comprises entre 25 et 100 individus par plante. Pour une durée d'hydrolyse de 2 ou $4 \mathrm{~h}$, la détection n'est pas significative, tandis que pour une hydrolyse de $20 \mathrm{~h}$, elle ne l'est que pour 4 plantes sur 15 .

\section{Application à l'étude du caractère de résistance mis en évidence chez les vignes « muscadines » (Muscadinia rotundifolia)}

Le comportement de 6 variétés de vignes «muscadines" a été étudié, comparativement à celui des variétés portegreffes classiques, $V$. riparia $\mathrm{cv}$ "Gloire " et $V$. rupestris $\mathrm{cv}$ «du Lot ». Pour chaque variété, 3 plantes ont été inoculées avec des concentrations comprises entre 500 et 1000 nématodes par plante.

Les résultats des tests ELISA pratiqués sur racines 3 mois après l'inoculation, puis un an après, sont donnés dans le tableau 2. Ces résultats confirment le haut niveau de résistance mis en évidence chez $M$. rotundifolia (BOUQUET, 1981), puisqu'aucune trace de multiplication virale n'est observée dans les racines 3 mois après leur inoculation. Au bout d'un an, les racines demeurent pratiquement exemptes de virus, les tests ELISA ne permettant de détecter sur quelques plantes, que des traces de virus à la limite de la sifnification (D.D.O. de 0,024 après $6 \mathrm{~h}$ d'hydrolyse du substrat !).

TABLEAU 2

Résultats des tests ELISA pratiqués sur des racines de $\mathrm{V}$. riparis, $\mathrm{V}$. rupestris et $\mathrm{M}$. rotundifolia, 3 mois et un an après leur inoculation par le virus du court-noué (GFV) au moyen de nématodes $\mathrm{X}$. index.

Results of immunosorbent assays (ELISA) performed on roots of V. riparia, V. rupestris and $\mathrm{M}$. rotundifolia, three months and one year after GFV inoculation by means of nematodes $\mathrm{X}$. index.

\begin{tabular}{|c|c|c|c|c|c|c|c|}
\hline \multirow[b]{2}{*}{ Temps d'hydrolyse du substrat } & & & \multicolumn{3}{|c|}{$\begin{array}{l}3 \text { mois après } \\
\text { l'inoculation }\end{array}$} & \multicolumn{2}{|c|}{$\begin{array}{l}12 \text { mois après } \\
\text { l'inoculation }\end{array}$} \\
\hline & & & $1 \mathrm{~h}$ & $4 \mathrm{~h}$ & $18 \mathrm{~h}$ & $1 \mathrm{~h}$ & $6 \mathrm{~h}$ \\
\hline D.D.O. Témoin infecté GFV & & & $+1,150$ & $>2,000$ & $>2,000$ & $+1,905$ & $>2,000$ \\
\hline \multirow[t]{2}{*}{$\begin{array}{l}\text { D.D.O. plantes inoculées par } X \text {. index } \\
V . \text { riparia cv «Gloire " ( } 3 \text { répétitions) }\end{array}$} & & $\begin{array}{l}1 \\
2 \\
3\end{array}$ & $\begin{array}{l}+0,351 \\
+0,066 \\
+0,421\end{array}$ & $\begin{array}{l}+1,317 \\
+0,296 \\
+1,466\end{array}$ & $\begin{array}{l}>2,000 \\
+1,103 \\
>2,000\end{array}$ & $\begin{array}{l}+1,719 \\
+1,559 \\
+1,540\end{array}$ & $\begin{array}{l}>2,000 \\
>2,000 \\
>2,000\end{array}$ \\
\hline & Moyenne & & $+0,279$ & $+1,026$ & $>2,000$ & $+1,606$ & $>2,000$ \\
\hline \multirow[t]{2}{*}{$V$. rupestris cv « du Lot » (3 répétitions) } & & $\begin{array}{l}1 \\
2 \\
3\end{array}$ & $\begin{array}{l}+0,880 \\
+1,109 \\
+0,664\end{array}$ & $\begin{array}{l}>2,000 \\
>2,000 \\
+1,877\end{array}$ & $\begin{array}{l}>2,000 \\
>2,000 \\
>2,000\end{array}$ & $\begin{array}{l}+1,583 \\
+1,951 \\
+1,896\end{array}$ & $\begin{array}{l}>2,000 \\
>2,000 \\
>2,000\end{array}$ \\
\hline & Moyenne & & $+0,884$ & $>2,000$ & $>2,000$ & $+1,810$ & $>2,000$ \\
\hline \multirow[t]{2}{*}{$M$. rotundifolia ( $6 \times 3$ répétitions) } & $\begin{array}{l}\text { Valeurs } \\
\text { extrêmes }\end{array}$ & & $\begin{array}{l}-0,013 \\
+0,003\end{array}$ & $\begin{array}{l}-0,023 \\
+0,003\end{array}$ & $\begin{array}{l}-0,048 \\
-0,003\end{array}$ & $\begin{array}{l}-0,016 \\
+0,009\end{array}$ & $\begin{array}{l}-0,008 \\
+0,024\end{array}$ \\
\hline & Moyenne & & $-0,006$ & $-0,013$ & $-0,030$ & $-0,005$ & $+0,003$ \\
\hline Ecart-type D.O. Témoins non inoculés: & & & 0,004 & 0,006 & 0,016 & 0,008 & 0,009 \\
\hline
\end{tabular}


Au contraire, les variétés porte-greffes utilisées comme témoins manifestent très rapidement leur sensibilité puisque les D.D.O. enregistrées sur les racines de $V$. rupestris cv "du Lot ", 3 mois après leur inoculation, atteignent 80 p. 100 de la D.D.O. observée sur les racines du témoin infecté GFV. Par contre, les D.D.O. enregistrées sur les racines de $V$. riparia cv «Gloire» sont nettement plus faibles, ce qui semblerait indiquer que ces 2 porte-greffes ont des comportements différents vis-à-vis du complexe $X$. index virus du court-noué. KUNDE et al. (1968) avaient déjà signalé que $V$. riparia $\mathrm{cv}$ «Gloire » et $V$. rupestris $\mathrm{cv}$ "du Lot" se situaient aux deux extrêmes de la gamme de sensibilité à $X$. index dans le genre Vitis. Boubals \& PISTRE (1978) confirment la tolérance de $V$. riparia cv «Gloire " mais n'observent pas de sensibilité particulière chez $V$. rupestris $\mathrm{cv}$ « du Lot », à la différence des auteurs précédents. Il faut d'ailleurs noter que la différence entre les 2 porte-greffes, nettement marquée 3 mois après l'inoculation, l'est beaucoup moins au bout d'un an.

Tout se passe comme si la tolérance de $V$, riparia $\mathrm{cv}$ "Gloire " à $X$. index entraînait un certain retard dans la contamination des racines par le virus. Mais, à la différence de ce qui est observé chez $M$. rotundifolia, ce retard n'est que temporaire puisqu'au bout d'un an, les systèmes racinaires des 2 porte-greffes sont pratiquement infectés d'une manière identique. De toute façon, les résultats concernant $V$. riparia et $V$. rupestris méritent un complément d'expérimentation, étendue éventuellement à d'autres variétés de porte-greffes (ex. : 3309 C, $41 \mathrm{~B}$, etc...) connues pour leurs comportements différents vis-à-vis de $X$. index (BOUBALS \& PISTRE, 1978).

\section{CONCLUSION}

Des tests immunoenzymatiques, pratiqués sur racines 3 mois après leur inoculation avec des doses élevées de nématodes $X$. index virulifères, permettent de caractériser d'une manière relativement fiable la sensibilité ou la résistance de certains génotypes à la transmission du virus du court-noué par son vecteur naturel.

On peut supposer que la résistance de $M$. rotundifolia est due à une inaptitude de $X$. index à inoculer le virus, liée sans doute à l'impossibilité pour le nématode de s'alimenter correctement sur les racines de cette espèce. DALMASso (comm. pers.) observe en effet la formation de zones nécrotiques au niveau des piqûres du nématode: cette réaction de type hypersensibilité semble interdire la reproduction du nématode. Lider (1973), Boubals \& PISTRE (1978) avaient déjà signalé que $M$. rotundifolia présentait un degré très élevé de résistance à la multiplication de $X$. index. Il est donc possible que nos observations rentrent dans le cadre d'une relation générale entre résistance au vecteur et résistance à la transmission du virus. Cependant, les travaux de BOUBALS \& PISTRE (1978) ont montré que l'appréciation directe de la résistance au nématode par examen des racines ne permettait absolument pas de tirer de conclusions quant aux possibilités réelles de transmission du virus. Le recours aux tests sérologiques après inoculation est donc nécessaire.

Il n'est d'autre part pas exclu qu'une certaine forme de résistance au virus proprement dite existe chez $M$. rotundifolia. En effet, la mise en évidence de traces de virus, le plus souvent peu ou pas significatives, dans certains échantillons de racines semblerait indiquer que le virus (mal inoculé ?) reste confiné, avec une très faible concentration, à certaines portions du système racinaire, ce qui expliquerait l'hétérogénéité de quelques observations effectuées à des dates différentes. Mais ce confinement n'est peut-être qu'une conséquence de la réaction des tissus de l'hôte à la piqûre du nématode. Des études complémentaires sont donc indispensables.

Du point de vue pratique, il n'est pas encore certain que la résistance. à la transmission du court-noué mise en évidence chez $M$. rotundifolia, soit culturalement intéressante. En effet, les résultats demandent à être confirmés au moyen de tests répétés sur plusieurs années car on ne peut pas exclure à priori l'hypothèse d'une contamination lente et très progressive de la plante. De plus, $M$. rotundifolia présente un ensemble de caractéristiques défavorables rendant son utilisation directe comme porte-greffe absolument impossible (BOUQueT, 1978) :

- reprise au bouturage nulle des sarments aoûtés,

- incompatibilité au greffage avec $V$. vinifera, bien que des différences importantes entre variétés de muscadines aient pu être mises en évidence par la méthode du greffage en vert (BOUQUET, 1980a),

- sensibilité à la chlorose calcaire,

- cycle végétatif très tardif et sensibilité au froid.

Nous avons donc entrepris d'introduire par hybridation cette résistance dans des génotypes de Vitis possédant les aptitudes culturales exigées des porte-greffes. Un tel programme se heurte à de nombreux obstacles liés à l'éloignement génétique entre $M$. rotundifolia et les espèces du genre Vitis. Cet éloignement se traduit par des difficultés de croisement, une stérilité extrêmement marquée des hybrides de $1^{\text {re }}$ génération et des déséquilibres génétiques et chromosomiques apparaissant en $2^{\mathrm{e}}$ génération $\mathrm{R} 1$ (= rétrocroisement des hybrides $\mathrm{F}_{1}$ par $V$. vinifera), entraînant des phénomènes de létalité ou sublétalité ainsi que des anomalies de développement chez de nombreux descendants. Toutefois, la plupart de ces difficultés sont actuellement surmontées ou en passe de l'être (BOUQUET, 1980b).

Mais l'utilisation effective en sélection de la résistance à la transmission du virus mise en évidence chez $M$. rotundifolia est en fait conditionnée par son déterminisme génétique. Celui-ci est en cours d'étude et les premiers résultats obtenus feront l'objet d'une prochaine publication.

Reçu le 21 janvier 1983. Accepté le 14 juin 1983.

\section{REMERCIEMENTS}

Les auteurs remercient Monsieur DunEz, Directeur de la Station de Pathologie végétale I.N.R.A. de Bordeaux et ses collaborateurs du laboratoire de virologie pour l'aide matérielle qu'ils ont fournie au cours de la réalisation de ce travail. 


\section{RÉFÉRENCES BIBLIOGRAPHIQUES}

Boubals D., Pistre R., 1978. Résistance de certaines Vitacées et des porte-greffes usuels en viticulture au nématode Xiphinema index et à l'inoculation par le virus du court-noué (GFV) in Génétique et amélioration de la vigne, I.N.R.A. Ed., Paris, 200-207.

Bouquet A., 1978. La Muscadine (Vitis rotundifolia Michx) et sa culture aux Etats-Unis. Conn. Vigne Vin, 12, 1-20.

Bouquet A., 1980a. Differences observed in the graft compatibility between some cultivars of Muscadine grape (Vitis rotundifolia Michx) and European grape (Vitis vinifera cv «Cabernet-Sauvignon »). Vitis, 19, 99-104.

Bouquet A., 1980b. Vitis $\times$ Muscadinia hybridization : a new way in grape breeding for disease resistance in France. Proc. II Symp. Int. Amélior. Vigne, Davis (Calif.), 42-61.

Bouquet A., 1981. Resistance to grape fanleaf virus in Muscadine grape inoculated with Xiphinema index. Plant Dis., 65, 791-793.

Bouquet A., 1983. Detection immunoenzymatique du virus du court-noué de la vigne (grape fanleaf virus) dans son vecteur Xiphinema index Thorne \& Allen. C.R. Acad. Sci. (proposé pour publication).

Bovey R., Brugger J. J., Gugerli P., 1980. Detection of fanleaf virus in grapevine tissue extracts by enzyme-linked immunosorbent assay (ELISA) and immune electron microscopy (IEM). Proc. 7th Meet. ICVG, Niagara Falls (Canada), 259-275.

Clark M. F., Adams A. N., 1977. Characteristics of the microplate method of enzyme-linked immunosorbent assay for the detection of plant viruses. J. gen. Virol., 34, 475-483.

Coiro M. I., Lamberti F., Agostinelli A., 1980. Cultivated plants and weeds as hosts for Xiphinema index. Proc. 7th Meet. ICVG, Niagara Falls (Canada), 153-155.

Dalmasso A., 1966. Méthode simple d'extraction des nématodes du sol. Rev. Ecol. Biol. Soc., 3, 473-478.

Dalmasso A., 1970. Contribution à l'étude des Longidoridae de France. Thèse Doct. ès Sci., Univ. Nice, $187 \mathrm{p}$.

Dalmasso A., 1978. Le point sur la désinfection nématicide du sol en viticulture. Déf. des Vég., 32, 63-71.
Hewitt W. B., Raski D. J., Goheen A. C., 1958. Nematode vector of soilborne fanleaf virus of grapevines. Phytopathology, 48, 586 595 .

Kunde R. M., Lider L. A., Schmitt R. V., 1968. A test of Vitis resistance to Xiphinema index. Am. J. Enol. Vitic., 19, 30-36.

Jimenez F., 1980. Resistance to fanleaf virus among grape cultivars and Vitis species. Master's thesis. Univ. California (Davis), $57 \mathrm{p}$.

Lider L. A., 1973. Etudes sur la résistance de quelques variétés de

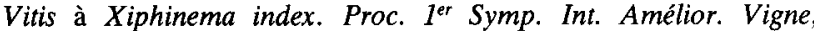
Siebeldingen (RFA), septembre 1973 (Abstract).

Meredith C. P., Lider L. A., Raski D. J., Ferrari N. L., 1982 Inheritance of tolerance to Xiphinema index in Vitis species. Am. J. Enol. Vitic., 33, 154-157.

Pracros P., Detienne G., Sarraquigne C., Dunez J., 1981. Intérêts comparés de l'indexage biologique sur semis de pêcher GF 305 et du diagnostic immunoenzymatique ELISA pour la détection de virus des espèces fruitières. Agronomie, 1 (7), 535-540.

Shanmuganathan N., 1982. Enzyme-linked immunosorbent assay to detect fanleaf virus in grapevines grown in containers. Plant Dis., 66, 704-707.

Vuittenez A., 1960. Nouvelles observations sur l'activité des traitements chimiques du sol pour l'éradication des virus de la dégénérescence infectieuse de la vigne. C.R. Acad. Agr. Fr., 46, 89-99.

Vuittenez A., Legin R., Kuszala J., Cardin-Muck M. C., 1972. Les virus « NEPO » chez la vigne et leurs nématodes vecteurs. Ann. Phytopathol., 4, 373-392.

Vuittenez A., Kuszala J., Legin R., Stocky G., Pejcinovski P. Heyd J. C., 1978. Phénomènes d'interaction entre souches de virus nepo affectant la vigne. 6th Meet. ICVG, Cordoba (Espagne), Septembre 1976. Monographias INIA, 59-68.

Walter B., Kuszala J., Vuittenez A., 1979. Diagnostic sérologique par les tests PALLAS et ELISA. Application aux virus de la rhizomanie de la betterave et du court-noué de la vigne. Ann. Phytopathol., 11, 568-569. 